\title{
A Nonlinear Electromagnetic Energy Harvesting System for Self-Powered Wireless Sensor Nodes
}

\author{
Kankan Li ${ }^{1}$, Xuefeng $\mathrm{He}^{1,2, *}{ }^{10}$, Xingchang Wang ${ }^{2}$ and Senlin Jiang ${ }^{1,2}$ \\ 1 Key Laboratory of Optoelectronic Technology and Systems of the Education Ministry of China, \\ Chongqing University, Chongqing 400044, China; 13629722420@163.com (K.L.); jiangsenlin@cqu.edu.cn (S.J.) \\ 2 College of Optoelectronic Engineering, Chongqing University, Chongqing 400044, China; \\ 13629722412@163.com \\ * Correspondence: hexuefeng@cqu.edu.cn; Tel.: +86-23-6510-4131
}

Received: 28 January 2019; Accepted: 7 March 2019; Published: 12 March 2019

\begin{abstract}
The Internet of things requires long-life wireless sensor nodes powered by the harvested energy from environments. This paper proposes a nonlinear electromagnetic energy harvesting system which may be used to construct fully self-powered wireless sensor nodes. Based on a nonlinear electromagnetic energy harvester (EMEH) with high output voltage, the model of a nonlinear interface circuit is derived and a power management circuit (PMC) is designed. The proposed PMC uses a buck-boost direct current-direct current (DC-DC) converter to match the load resistance of the nonlinear interface circuit. It includes two open-loop branches, which is beneficial to the optimization of the impedance matching. The circuit is able to work even if the stored energy is completely drained. The energy harvesting system successfully powered a wireless sensor node. Experimental results show that, under base excitations of $0.3 \mathrm{~g}$ and $0.4 \mathrm{~g}$ (where $1 \mathrm{~g}=9.8 \mathrm{~m} \cdot \mathrm{s}^{-2}$ ) at $8 \mathrm{~Hz}$, the charging efficiencies of the proposed circuit are $172 \%$ and $28.5 \%$ higher than that of the classic standard energy-harvesting (SEH) circuit. The experimental efficiency of the PMC is $41.7 \%$ under an excitation of $0.3 \mathrm{~g}$ at $8 \mathrm{~Hz}$.
\end{abstract}

Keywords: energy harvesting; vibration; electromagnetic induction; power management circuit; wireless sensor node; self-powered

\section{Introduction}

Nowadays, most wireless sensor nodes and portable electronic devices are powered by traditional chemical batteries. To overcome the drawbacks of batteries such as limited operating life, expensive maintenance/replacement cost and chemical pollution, energy harvesters collecting electrical energy from a variety of ambient sources (solar energy, thermal energy, wind energy, and vibration energy) have received a great deal of attention in recent years [1-7]. Various forms of miniaturized energy harvesters have been developed to power wireless sensor nodes and small electronic devices. For the relatively low output powers of the energy harvesters and the special requirements of the electrical loads on the electrical sources, a power management circuit (PMC) is essential to efficiently store and release the collected energy to the loads [8-10]. Moreover, optimal data scheduling, admission control, anti-collision, and sensitive and efficient energy harvesting for backscatter sensor networks have been studied [11-13]. The energy detection technology for Decision Fusion in multiple-input multiple-output (MIMO) Wireless Sensor Networks, the decision fusion algorithms, and distributed detection have been discussed [14-17].

Different types of energy harvesters require various PMCs. For example, the standard energy-harvesting (SEH) circuit, synchronous charge extraction (SCE) circuit, parallel synchronized switch harvesting on inductor (P-SSHI) circuit, or series synchronized switch harvesting on inductor 
(S-SSHI) circuit have been proposed to manage the piezoelectric energy harvesters (PEHs) with the characteristics of high output voltage and low current [18-21]. Electromagnetic energy harvesters (EMEHs) possess the characteristics of low output voltage and high output current. The voltage with hundreds of millivolts is generally lower than the forward conduction voltage of the rectifier diode or the working voltage of most wireless senor nodes. This complicates the PMC by an indispensable voltage-boosting element. A synchronous magnetic flux extraction (SMFE) circuit uses coil inductance to construct a boost direct current-direct current (DC-DC) converter circuit. However, the switch control of the SMFE circuit is not yet self-powered and requires an external power supply [22,23]. In addition, the voltage multiplying circuit adopts a series of diodes and capacitors to boost the voltage. However, the multiplying circuit is complex and causes high power consumption, which decreases the charging speed [24].

Three types of the models of electromagnetic energy harvesting systems have been developed. First, a linear electromagnetic energy harvester is connected to a linear interface circuit, which is a pure resistive electrical load [25]. Second, a nonlinear electromagnetic energy harvester is connected to a linear circuit [26]. Third, a linear electromagnetic energy harvester is connected to a nonlinear circuit containing non-resistive components [27]. However, the model of a nonlinear electromagnetic energy harvester connected to a nonlinear circuit has not been investigated, which will be discussed in this paper.

Our group has developed an impact-based nonlinear EMEH with arrays of magnet and coil [26]. The most prominent characteristic of this device is the high output voltage, with the voltage of $16 \mathrm{~V}$ across an $11 \mathrm{k} \Omega$ resistor under the base excitation of $0.3 \mathrm{~g}$ at $8.5 \mathrm{~Hz}$. The resistive impedance-matching method is usually adopted to match the internal resistance of the harvester, neglecting the effects of non-resistive components [28-34]. There are many ways to produce the control signals for the impedance matching. Lefeuvre et al. [28] used an active crystal oscillator to produce a control signal to match the impedance of PEHs. Shen et al. [29] used the active crystal oscillator to produce a control signal for the impedance matching of EMEHs. However, the operating voltage of the active crystal ranges from $1.6 \mathrm{~V}$ to $5.5 \mathrm{~V}$, which puts forward additional requirement on the output voltage of the harvester. Kong et al. [30] and Guo et al. [31] used a square-wave-generating circuit to produce a control signal. The control circuit is powered by a storage element; as a result, once the storage energy is exhausted, the system cannot work normally again. Chen et al. $[32,33]$ adopted a square-wave-generating circuit to produce a control signal and used a capacitor after rectifiers to power the control circuit. A voltage stabilizer after the capacitor was used to stabilize the control signal, which would affect impedance matching and cause energy dissipation.

This paper proposes a nonlinear interface circuit model for the nonlinear EMEHs with high output voltage and designs an autonomous PMC to power a wireless sensor node. The PMC applies the average input resistance of the buck-boost converter to match the load resistance of the nonlinear interface circuit, instead of roughly matching the internal resistance of the harvester. The circuit mainly contains two open-loop branches. The first branch is the main branch powered by most of the coils of the EMEH to store the harvested energy, and the second branch is the control branch that is individually powered by the rest of the coils. The signal generated by the second branch controls the operation of the main branch to store the harvested energy. Furthermore, the experimental results demonstrate that, compared with the SEH circuit, the proposed PMC transfers more energy from the harvester to the load and improves the charging efficiency. The joint design of EMEH and PMC improves the whole performance of the system. In addition, a wireless sensor node powered by the nonlinear electromagnetic energy harvesting system is developed and tested.

The remainder of this paper is organized as follows. The structure of the EMEH and the nonlinear model are introduced in Section 2. After giving an SEH circuit as a comparison, Section 3 presents the proposed power management circuit. Section 4 describes the constitution and operation process of the self-powered wireless sensor node. In Section 5, the experimental results are presented and discussed. Finally, conclusions are drawn in Section 6. 


\section{Electromagnetic Energy Harvester and Nonlinear Model}

\subsection{Device Structure}

As shown in Figure 1, the harvester is mainly composed of the magnetic array, coil array, springs, rollers, and frames. Thin rectangular permanent magnets, with the magnetic field in the thickness direction, are lined up next to each other along the width direction to form rows of magnets. Similarly, rectangular metal coils form coil rows between any two adjacent magnetic rows. The magnet array and the coil array are fixed on the inner frame and outer frame, respectively. Four springs are attached to the ends of the inner frame with initial gaps between the free ends of the springs and the walls of the outer frame.

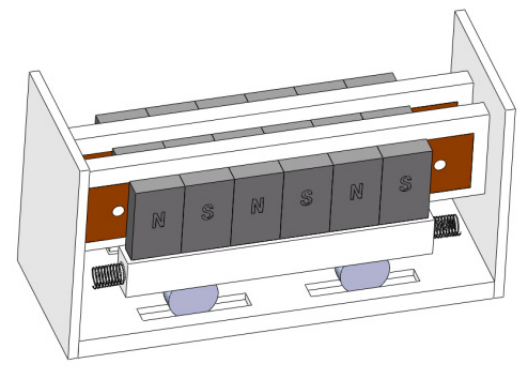

(a)

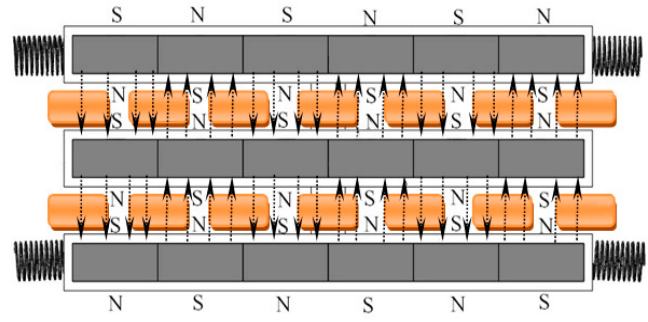

(b)

Figure 1. Schematic of the electromagnetic vibration energy harvester: (a) overall structure; (b) magnet and coil arrays.

Horizontal base excitations make the inner frame move with respect to the outer frame on the rollers; as a result, the magnetic flux through the coils changes and an induced electromotive force occurs in the coils. The springs are helpful to decrease the energy loss during the collisions between the inner and outer frames [26].

\subsection{Harvester Optimization}

The influences of the initial gap and the stiffness of the springs on the electrical outputs have been numerically analyzed in our previous work [26]. To further improve the energy-scavenging efficiency, the gap between two adjacent magnet rows decreases from $7 \mathrm{~mm}$ to $5 \mathrm{~mm}$. After analyzing the effects of the thickness of the magnet, the thickness of the coil, the diameter of the coil, and the size of the inner dimension of the coils on the output power, we obtained the optimized parameters of the EMEH, as shown in Table 1.

Table 1. Optimized parameters of the EMEH.

\begin{tabular}{cc}
\hline Parameter & Value \\
\hline Separation between two magnet rows & $5 \mathrm{~mm}$ \\
Magnet dimension & $20 \mathrm{~mm} \times 10 \mathrm{~mm} \times 4 \mathrm{~mm}$ \\
Coil dimension & $18 \mathrm{~mm} \times 9 \mathrm{~mm} \times 3 \mathrm{~mm}$ \\
Dimension of coil through a hole & $12 \mathrm{~mm} \times 3 \mathrm{~mm} \times 3 \mathrm{~mm}$ \\
Wire diameter & $50 \mu \mathrm{m}$ \\
Number of magnets in each row & 6 \\
Number of magnet rows & 3 \\
Number of coils in each row & 7 \\
Number of coil rows & 2 \\
\hline
\end{tabular}

\subsection{Modeling and Simulation}

The EMEH is equivalent to a voltage source in series with an internal resistance $R_{W}$ and an internal inductance $L_{W}$. The equivalent circuit of the nonlinear energy harvesting system is given in Figure 2 . 
The system is composed of a nonlinear electromagnetic energy harvester and a nonlinear interface circuit. The circuit may be denoted by a resistor with a full-bridge rectifier and a regulating capacitor.

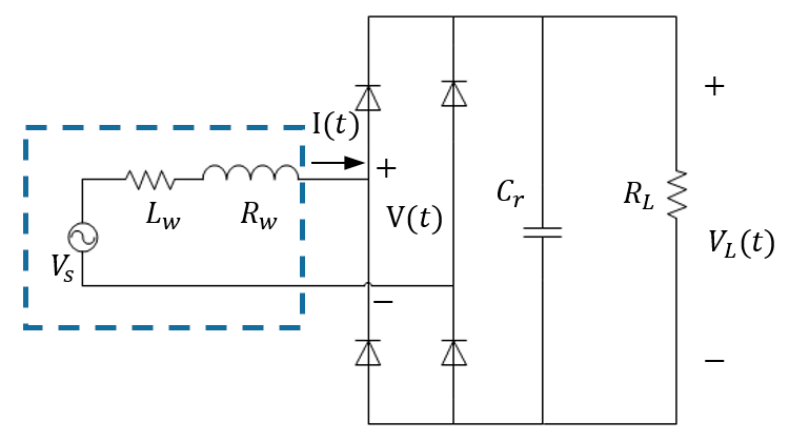

Figure 2. Equivalent circuit of a nonlinear electromagnetic energy harvesting system.

A nonlinear electromagnetic energy harvester connecting to a linear resistive has been studied [26]. Non-resistive components connecting to linear electromagnetic energy harvesters may be expressed by a signum function [27]. Under harmonic base excitation $\ddot{x}_{b}(t)=A_{0} \sin (2 \pi f t)$, by letting $\mathrm{x}(t)$ denote the displacement of the inner frame with respect to the outer frame or the base and $\mathrm{I}(t)$ the collected current, the governing equations of the nonlinear electromagnetic energy harvesting system can be expressed as $[26,27,34]$ :

$$
\left\{\begin{array}{l}
M x(t)+C_{m} \dot{x}(t)+k(|x(t)|-S)+\frac{\dot{x}(t)}{|\dot{x}(t)|} \mu M g+\kappa I(t)=-M \ddot{x}_{b}(t) \\
L_{w} \dot{I}(t)+R_{w} I(t)+V(t)=\kappa \dot{x}(t)
\end{array}\right.
$$

where $\mu$ is the coefficient of rolling friction, $M$ is the mass of the inner frame, $C_{m}$ is the mechanical damping coefficient, $S$ is the initial gaps between the free ends of the springs and the opposite walls of the outer frame, and $k$ is the effective stiffness of the springs. Here, $C_{m}$ and $k$ are piecewise functions. The electromechanical coupling coefficient $\kappa$ is given by $\kappa=\frac{d \Phi}{d x}$, where $\Phi$ is the total magnetic flux through the coil array. The coefficient varies with the displacement of the inner frame with respect to the outer frame.

For low-frequency excitations $w L_{w} \ll R_{w}+R_{L}$ [27], therefore, we can obtain:

$$
R_{w} I(t)+\left(V_{r}+V_{L}(t)\right) \operatorname{sgn}(I(t))=\kappa \dot{x}(t)
$$

where $V_{r}$ is the voltage drop of the rectifier, and $\operatorname{sgn}(\cdot)$ is the signum function defined as:

$$
\operatorname{sgn}(\cdot)=\frac{\dot{ }}{|\cdot|}=\left\{\begin{array}{c}
1, \cdot>0 \\
-1, \cdot<0
\end{array}\right.
$$

According to Equations (2) and (3), the sign of $\mathrm{I}(t)$ is the same with that of $\dot{x}(t)$.

The harvested energy can be transferred to the loads only when the rectifier is on. If at time $t_{1}$, $\left|V\left(t_{1}\right)\right|>V_{r}+V_{L}\left(t_{1}\right)$, where $V_{L}\left(t_{1}\right)$ is the voltage across the regulating capacitor, then the rectifier is on, and the current may be expressed as [27]:

$$
\mathrm{I}(t)=\left(C_{r} \dot{V}_{L}(t)+\frac{V_{L}}{R_{L}}\right) \operatorname{sgn}(\dot{x}(t)) .
$$

Substituting Equation (4) into Equation (2) leads to:

$$
\kappa|\dot{x}(t)|=R_{w}\left(C_{r} \dot{V}_{L}(t)+\frac{V_{L}}{R_{L}}\right) \operatorname{sgn}(\dot{x}(t))+\left(V_{r}+V_{L}(t)\right) \operatorname{sgn}(\dot{x}(t)) .
$$


Equation (5) can be rewritten as:

$$
\kappa|\dot{x}(t)|-V_{r}=R_{w} C_{r} \dot{V}_{L}(t)+\frac{1}{r} V_{L}(t),
$$

where $\mathrm{r}=\frac{R_{L}}{R_{w}+R_{L}}$.

The effect of the electromechanical coupling on the harvester dynamics can be written as:

$$
\mathrm{kI}(t)=C_{e} \dot{x}(t)-\frac{\kappa V_{r}}{R_{w}+R_{L}} \operatorname{sgn}(\dot{x}(t))+\mathrm{\kappa r}_{r} \dot{V}_{L}(t) \operatorname{sgn}(\dot{x}(t)),
$$

where $C_{e}=\frac{\mathrm{k}^{2}}{R_{w}+R_{L}}$.

As the coefficient of rolling frication is as low as 0.002 , the frication force is neglected in the simulations [26,35]. The governing equations of the system can be rewritten as:

$$
\left\{\begin{array}{l}
M x(t)+\left(C_{m}+C_{e}\right) \dot{x}(t)+k(|x(t)|-S)-\frac{\kappa V_{r}}{R_{w}+R_{L}} \operatorname{sgn}(\dot{x}(t))+\kappa r C_{r} \dot{V}_{L}(t) \operatorname{sgn}(\dot{x}(t))=-M \ddot{x}_{b}(t) . \\
L_{w} \dot{I}(t)+R_{w} I(t)+V(t)=\kappa \dot{x}(t)
\end{array} .\right.
$$

The harvested energy $E_{L}$ is the energy delivered to the load resistance $\left(R_{L}\right)$ over a period of $T$, and the average power can be calculated as:

$$
P_{L}=\frac{1}{T} \int_{0}^{T} \frac{V_{L}^{2}(t)}{R_{L}} d t
$$

By using the parameters listed in Table 1 and setting $\mathrm{M}=0.12 \mathrm{~kg}, \mathrm{Cm}=1.36 \mathrm{~N} \cdot \mathrm{s} / \mathrm{m}, \mathrm{k}=400 \mathrm{~N} / \mathrm{m}$, $\mathrm{S}=2.5 \mathrm{~mm}, L_{W}=746 \mathrm{mH}, R_{W}=10.5 \mathrm{k} \Omega, V r=0.8 \mathrm{~V}$, and $C r=10^{-2} \mu \mathrm{F}$, numerical simulations were conducted based on the above model using MATLAB. Figure 3 summarizes the simulated output power versus electrical resistances under base excitations with the same amplitude of $0.2 \mathrm{~g}$ but different frequencies of 5, 6, 7, 8, 9, and $10 \mathrm{~Hz}$. The output power reaches the maximum values when the load impedance is about $11 \mathrm{k} \Omega$, which is close to the internal resistance of the coil array $(10.5 \mathrm{k} \Omega)$.

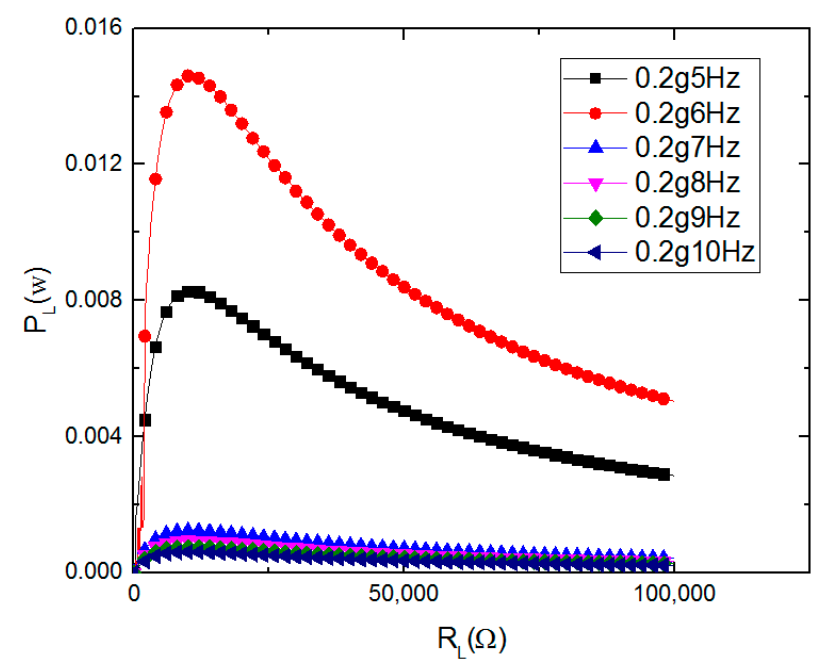

Figure 3. Average power versus load resistance at different excitation frequencies. 


\section{Energy Harvesting Circuit}

\subsection{A Standard Energy-Harvesting Circuit}

Since the EMEH produces a high AC voltage and a wireless sensor node requires a DC voltage input, an alternating current-direct current (AC-DC) rectifier is indispensable. The EMEH is equivalent to a voltage source in series with an internal resistance and an internal inductance. As shown in Figure 4, SEH circuit is the simplest PMC. The input ends of the full-wave rectifier circuit are connected to the ends of the coils of the EMEH. The output of the full-wave rectifier circuit is connected to a capacitor, which stores the collected energy $[25,28]$.

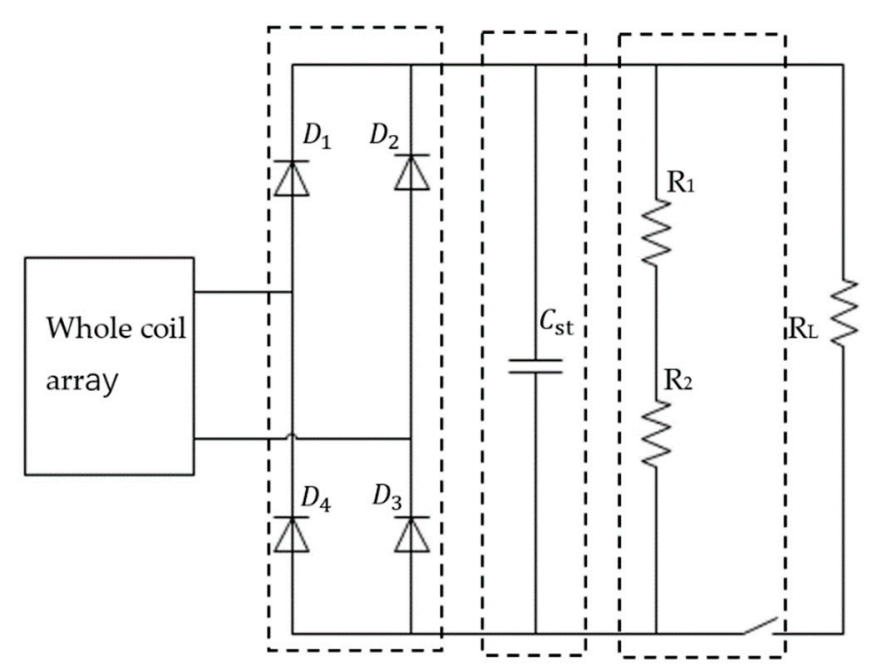

Figure 4. Standard energy-harvesting circuit.

A discharge module is needed to release the stored energy in the capacitor to power the electrical loads, which is implemented by a voltage detection circuit. Several resistors connected in series are parallel connected with the capacitor to detect the capacitor voltage. The resistance must be large enough, above the mega-ohm, to reduce the power cost. The storage capacitor Cst also should be large enough to store sufficient energy. In the charging process, the energy consumption of the resistance branch is very low, which is negligible compared with the charged electricity. The voltage detection circuit is briefly expressed by a switch symbol and a resistor branch. The actual charging or discharging process of the storage capacitor is jointly controlled by a low-power comparator and two single-pole double-throw (SPDT) analog switches.

A voltage detection circuit was recently reported by Han et al. [36]. The structure of the circuit is shown in Figure 5. There is a wide voltage range between the upper threshold voltage and the lower threshold voltage. When the voltage of the capacitor reaches the upper threshold voltage, the capacitor begins to discharge and provides an appropriate output voltage to the loads. With the energy consumption of the loads, the voltage of the storage capacitor decreases. When the voltage is lower than the lower threshold voltage, the discharging process is finished and the connection with the load is disconnected. Then, the storage capacitor could be charged again in the next cycles. Therefore, the wireless sensor node is switched on and off intermittently, along with the charging and discharging of the storage capacitor. The upper and lower threshold voltages were adjusted in this work. 


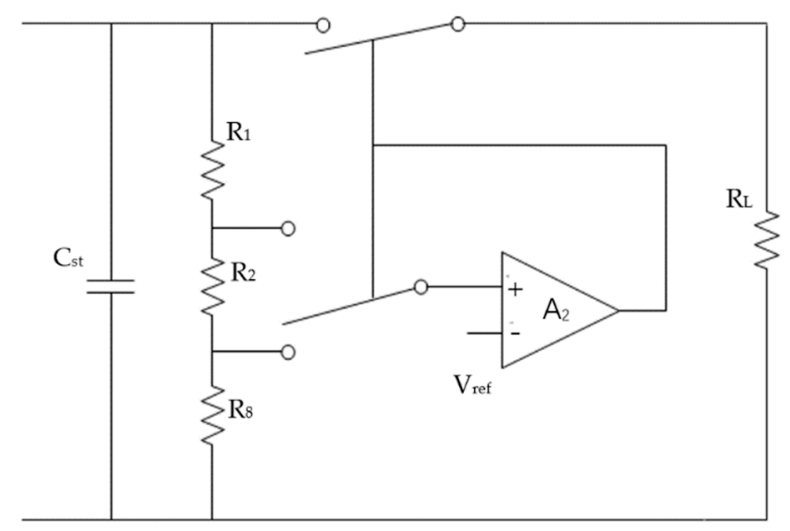

Figure 5. Voltage detection circuit [36].

\subsection{Proposed Power Management Circuit}

For EMEHs with high output voltage, there is no need to boost the voltage. By referring the resistive impedance-matching methods for piezoelectric energy harvesters [21-27], this paper proposed a PMC for EMEHs with a two-stage power conditioning circuit consisting of an AC-DC converter followed by a DC-DC converter. Here, the circuit applies a buck-boost DC-DC converter to match the load resistance of the nonlinear circuit, instead of roughly matching the internal resistance of the harvester. The power conditioning circuit intends to maximize the power extracted from EMEHs.

As shown in Figure 1, the EMEHs with high output voltage include a coil array and a magnet array. In this study, the coils of the harvester are divided into two groups to power two branch circuits of the PMC, respectively. The main branch of the PMC is an energy storage branch powered by most of the coils. The secondary branch is a switch control module powered by the rest of the coils. The PMC includes a rectifier module, a buck-boost DC-DC conversion module, a switch control module, an energy storage device, a discharge module (voltage detecting circuit and voltage stabilizer), and the electrical loads, as shown in Figure 6. The voltage conversion module is important in the whole circuit, because it is responsible for the charging of the capacitor. The switch control module generates a square wave with a fixed duty ratio to control the operation of the main branch. The energy storage device is a capacitor rather than a battery. The discharge module of the PMC also employs the same voltage detection circuit with the SEH circuit. The voltage stabilizer provides a standard operation voltage for the loads.

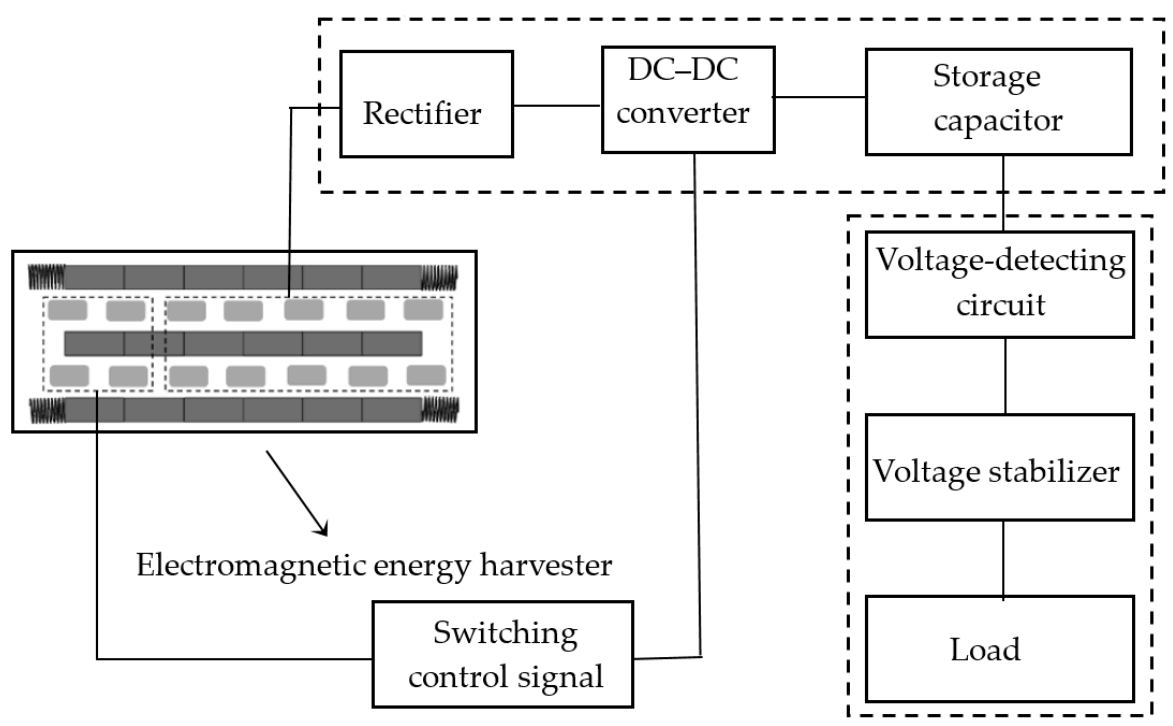

Figure 6. Block diagram of an electromagnetic energy harvester and a power management circuit. 
As shown in Figure 7, the main branch of the PMC includes an AC-DC full-bridge rectifier circuit, a buck-boost DC-DC switch conversion circuit, a capacitor, and a voltage detecting circuit. The input port of the rectifier circuit is connected to the output port of the most of the coils. The output voltage of the harvester is rectified and directly connected to the input port of the DC-DC conversion circuit. The control signal of the DC-DC conversion circuit comes from the secondary branch, which produces a square wave signal with a fixed duty ratio. The square wave signal affects the impedance matching and controls the charging process. The output port of the DC-DC conversion circuit is connected to the storage capacitor, and the voltage detection circuit is connected in parallel to two ends of the capacitor. The capacity of the storage capacitor, the upper threshold voltage, and the lower threshold voltage can be modified to meet the requirements of different loads.

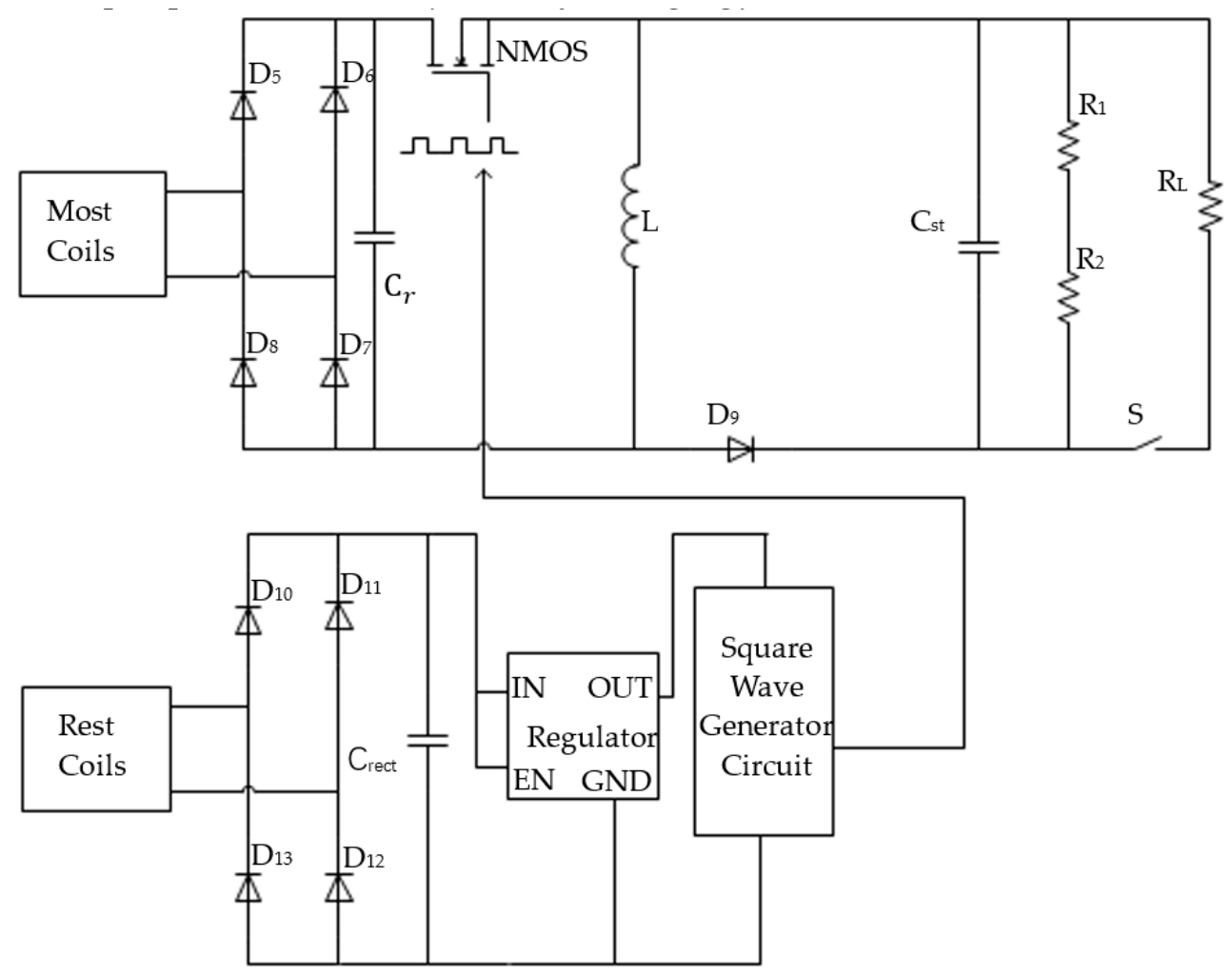

Figure 7. Schematic of the proposed power management circuit.

As shown in Figure 7, the secondary branch of the PMC mainly contains an AC-DC rectifier, a filter capacitor, a voltage regulator, and a square wave generator circuit. After rectifying, filtering and regulating, the output voltage of the rest of the coils supplies a power source to the square-wave-generating circuit. For the general feedback closed-loop circuit, the power supply comes from the storage device, and the circuit cannot work if the energy storage is drained. For common single branch circuit, the power supply is the filter capacitor after the rectifier bridge, which would affect impedance matching and cause energy dissipation. In this paper, to solve these issues, the control circuit is individually powered by the coil group with the fewer coils, which forms an open-loop structure with two branches. 
In the middle of Figure 7, in order to increase the output power of the harvester, a buck-boost DC-DC switching converter working in discontinuous conduction mode (DCM) is used [28-34]. The working principle is described as follows. When the switch tube (N-metal-oxide-semiconductor, NMOS) is closed, the diode D9 is nonconductive due to reverse bias, and the energy is accumulated in the inductor $L$. When the switch tube is switched off, the diode D9 is conductive. Then, the inductor, the diode, and the capacitor form a closed-loop circuit and the induced current is generated. When the DC-DC converter works in the DCM, the input terminal of DC-DC circuit behaves like a resistance and matches the load resistance of the nonlinear circuit to increase the output power of the system. The equivalent resistance can be expressed as [28-34]:

$$
R_{i n}=\frac{2 L f_{s w}}{d^{2}}
$$

where $f_{s w}$ is the switching frequency of the converter and $d$ is the duty ratio. The average input resistance of the converter $R_{\text {in }}$ can be used to substitute load resistance $R_{L}$ of the nonlinear circuit. Therefore, the output power can be adjusted by changing $f_{s w}$ and $d$.

\subsection{Square-Wave-Generating Circuit}

The control signal of a DC-DC converter is produced by a basic square wave generator, as shown in Figure 8. Kong et al. [30] and Chen et al. [33] adopted the square wave generator to control the switch of the DC-DC converter of piezoelectric energy harvesting systems. The circuit with the same function is used here. The square-wave-generating circuit is mainly realized by a low-power comparator and a resistor-capacitance (RC)-charging or -discharging circuit. In the charging process, D14 is conductive and $\mathrm{C} 1$ is charged by the parallel of R6 and R7. In the discharging process, D14 is nonconductive and $\mathrm{C} 1$ is discharged by R7. If R7 is much larger than R6, the charging rate of this circuit is fast, and the discharging rate is slow. By selecting appropriate $\mathrm{R} 3, \mathrm{R} 4, \mathrm{R} 5, \mathrm{R} 6, \mathrm{R} 7$, and $\mathrm{C} 1$, this circuit can produce the desired square-wave control signal. The power $\mathrm{V}_{c c}$ is provided by the rest of coils of the EMEH.

The cycle of the square-wave-generating circuit is:

$$
\mathrm{T}=\left(R_{7}+\frac{R_{6} * R_{7}}{R_{6}+R_{7}}\right) \times C_{1} \times \ln 2
$$

Therefore, the frequency is:

$$
\mathrm{f}=\frac{1}{\mathrm{~T}}
$$

The duty ratio is:

$$
d=\frac{R_{6}}{2 R_{6}+R_{7}} .
$$

The frequency and duty ratio of the generated square-wave control signal can be obtained from Equations (12) and (13). The frequency of the square wave is much higher than the vibration frequency of the harvester. For example, the vibration frequency of the EMEH prototype is below $10 \mathrm{~Hz}$ and the frequency of the square wave is about $1 \mathrm{kHz}$. The generated signal is connected to the gate of the NMOS switch of the main branch, through a protective resistor, to control the energy storage process. 


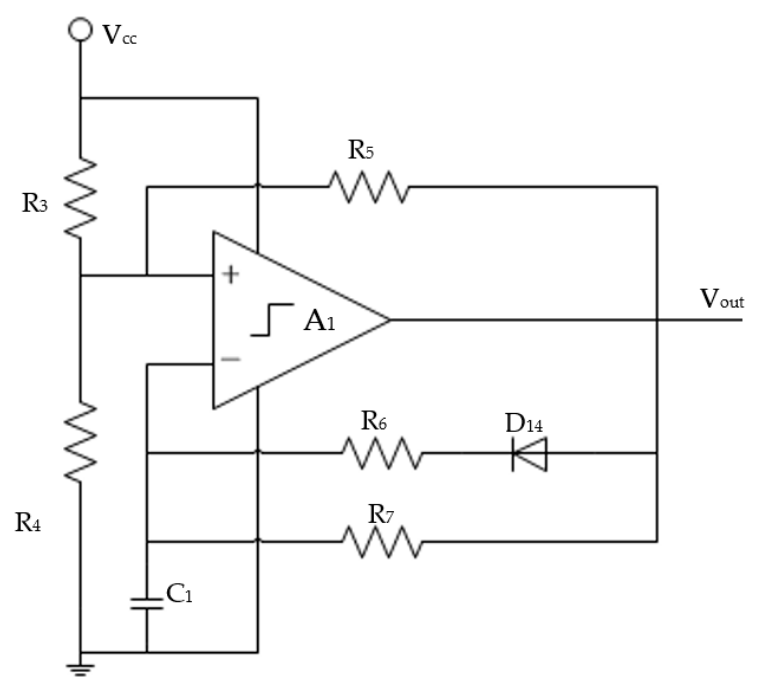

Figure 8. Square-wave generation circuit.

\section{Wireless Sensor Node}

The electrical load of this work is a wireless sensor node, which is composed of a sensor, a low-power microprocessor, and a low-power transceiver. The transmission mechanism of the wireless sensor node is based on ZigBee wireless communication technology. The whole system is shown in Figure 9. A stable voltage for the wireless sensor node is provided by a low dropout regulator.

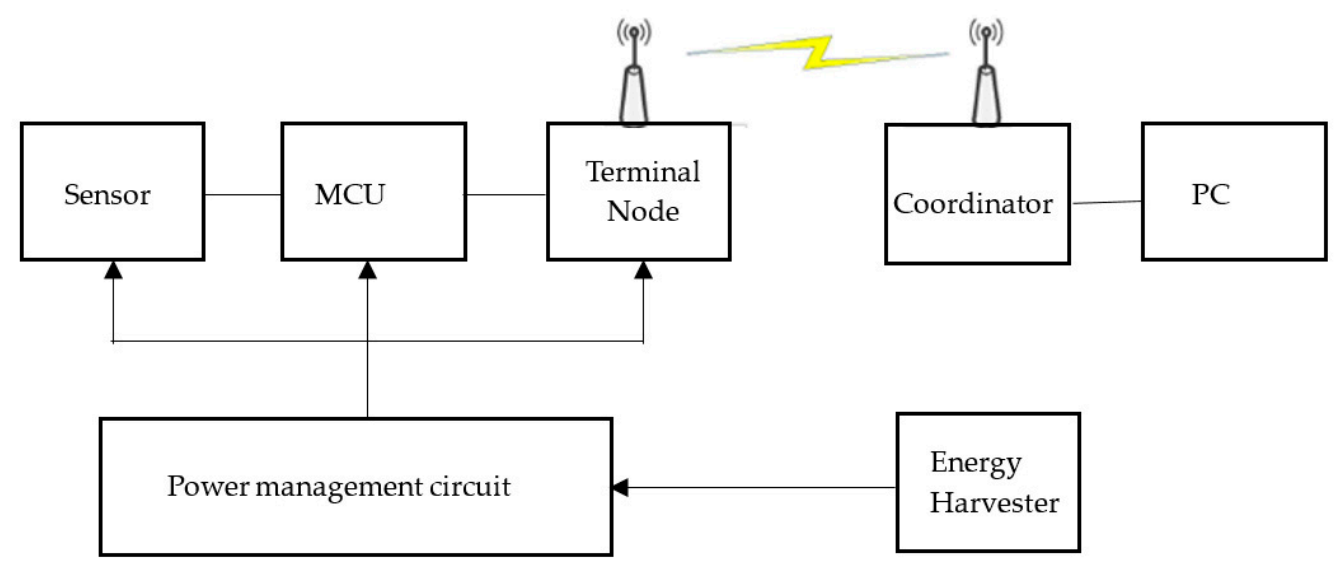

Figure 9. Schematic of the self-powered wireless sensor node.

The energy supplying system and wireless sensor node are shown in Figure 10. The electrical output of the energy harvester is generally low and cannot be used to directly power the wireless sensor nodes. In most cases, the energy supplying system is used to intermittently power these nodes. The charging and discharging process are periodically operating. In addition, the microcontroller unit (MCU) works in low-power mode in spare time to reduce power dissipation. The detailed working process is shown in Figure 10b. 


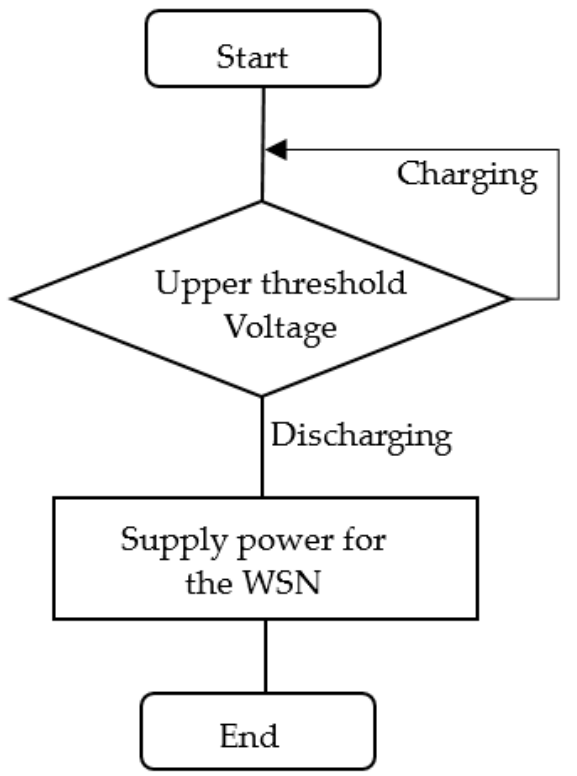

(a)

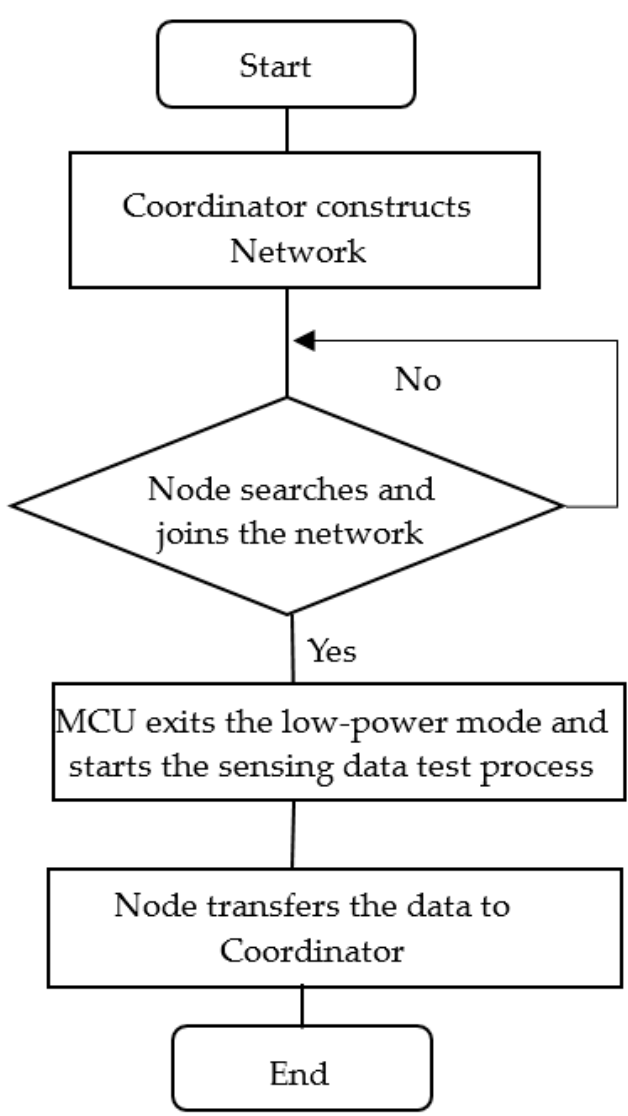

(b)

Figure 10. Block diagrams of the operating process: (a) power supply module; (b) wireless sensor node module.

\section{Experimental Results and Discussions}

\subsection{Experiments of the Harvester Prototype}

An EMEH prototype with the parameters listed in Table 1 was fabricated, as shown in Figure 11. The prototype contained 3 rows of magnets and 2 rows of coils. The total number of the coils for the prototypes was 14 . The internal resistance and inductance of EMEH were measured by an impedance analyzer (637X, Microtest, Taipei, Taiwan). The impedance of whole EMEH including 14 coils was $10.5 \mathrm{k} \Omega$ and the impedance of 10 coils was $7.5 \mathrm{k} \Omega$. The inductance of the EMEH was $746 \mathrm{mH}$ which can be ignored compared with the resistance of the coils under low-frequency base excitations.

The energy harvesting performance of the prototype was experimentally characterized on a shaker (ET-139). The shaker was driven by a harmonic voltage signal enlarged by a power amplifier (PA-151). The acceleration of shaker was measured by an accelerometer (DYTRAN 3056B2, Labworks, Costa Mesa, CA, USA) and monitored by a digital oscilloscope (DSOX3012A, Agilent, San Francisco, CA, USA). The output voltage was also monitored by the oscilloscope. The recorded time history of the open-circuit voltage under base excitation of $0.3 \mathrm{~g}$ at $8 \mathrm{~Hz}$ is given in Figure 12. The peak output voltage was about $50 \mathrm{~V}$, meeting the voltage requirement of the proposed PMC. 


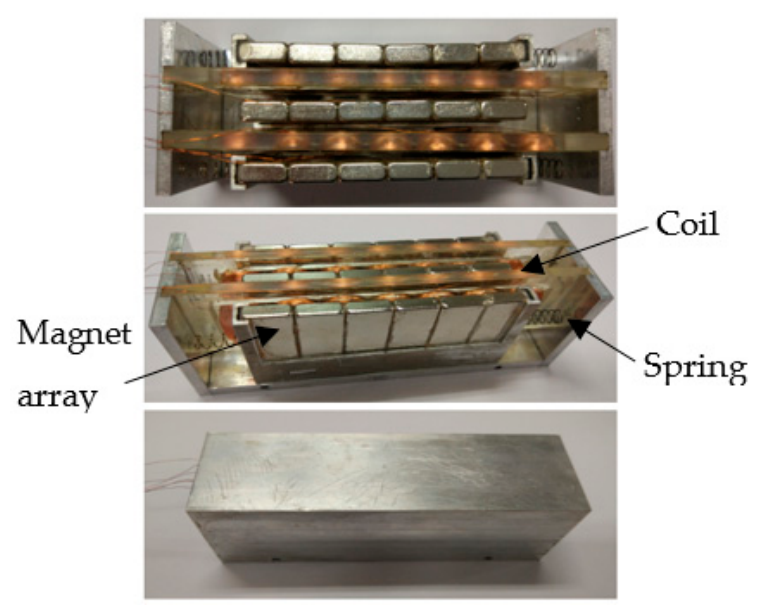

Figure 11. Photograph of the harvester prototype.

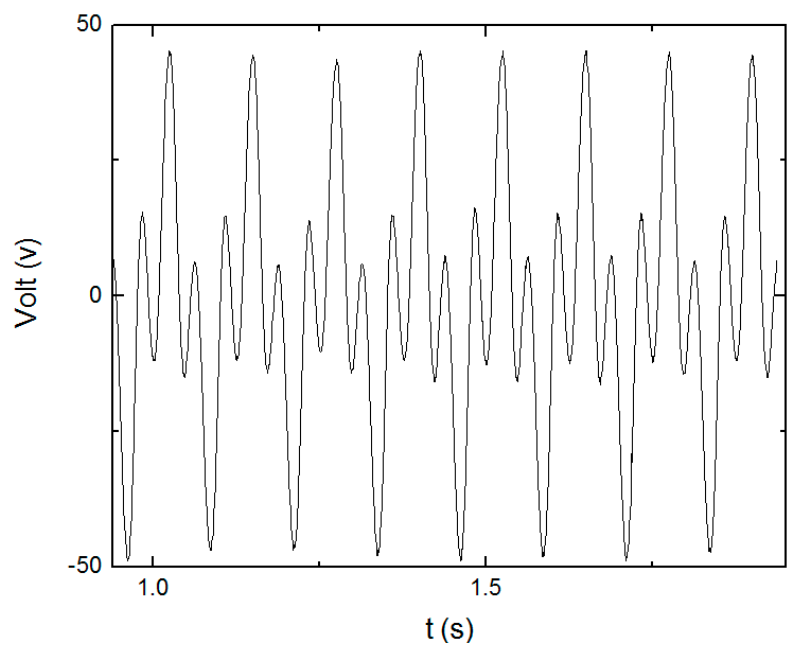

Figure 12. Output open-circuit voltage of an electromagnetic energy harvester.

To investigate the electrical properties of the harvester, the root mean square (RMS) voltages across different resistors were measured. The output powers of the harvesters were worked out from the experimental RMS voltages and the resistances. Figure 13 gives the relationships between the output power and the load resistance under the base excitation of $0.1,0.2$ and $0.3 \mathrm{~g}$ at $5,6,7,8,9$, and $10 \mathrm{~Hz}$, respectively. The output power tends to increase first and then decrease. Furthermore, the maximum output power appears when the resistance is about $11 \mathrm{k} \Omega$, very close to the total resistance of the coil array of $10.5 \mathrm{k} \Omega$. It is found that, when the resistance changed, there was a sudden jump of the output power under base excitation of $0.1 \mathrm{~g}$ at $6 \mathrm{~Hz}$. These jumps come from the effects of the external electrical resistance. As we know, the output power of the harvester is significantly affected by the external resistance connected to it. For small external resistance, according to Equation (4), the current in the coils is relatively large and the current produces a relatively large electromagnetic force between the coils and the magnets to decrease the relative velocity between them. Therefore, under the same base excitation, the inner frame is easier to collide with the outer frame when the external resistance is higher. Under excitation of $0.1 \mathrm{~g}$ at $6 \mathrm{~Hz}$, the inner and outer frames do not collide with each other when the resistance is smaller than $10 \mathrm{k} \Omega$, and collide each other when the resistance is higher than $11 \mathrm{k} \Omega$. The collisions promotes the electrical output. As a result, a sudden jump of the output power occurs under $0.1 \mathrm{~g}$ at $6 \mathrm{~Hz}$. For the same reason, the sudden jumps are observed under $0.2 \mathrm{~g}$ at $8 \mathrm{~Hz}$ and $0.3 \mathrm{~g}$ at $8 \mathrm{~Hz}$. The experimental observation verified that the jumps are caused by the collisions. 


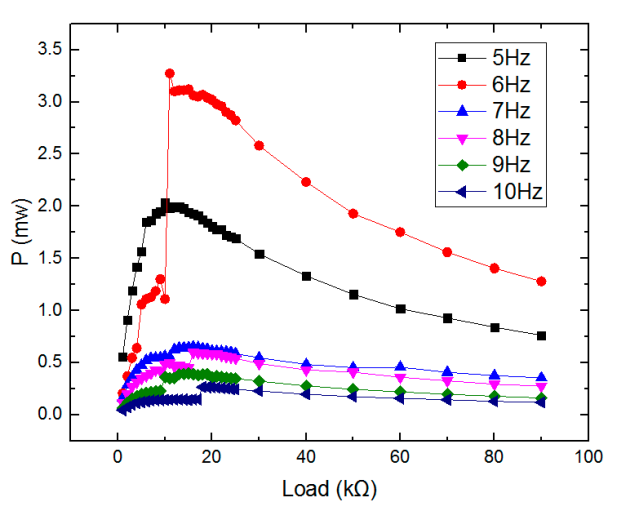

(a)

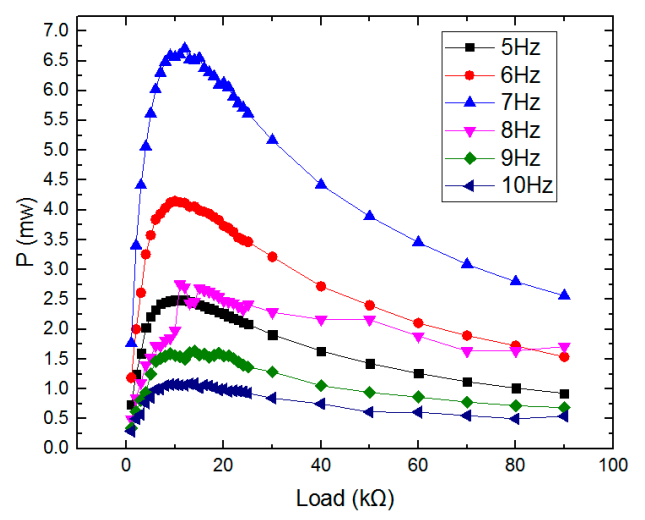

(b)

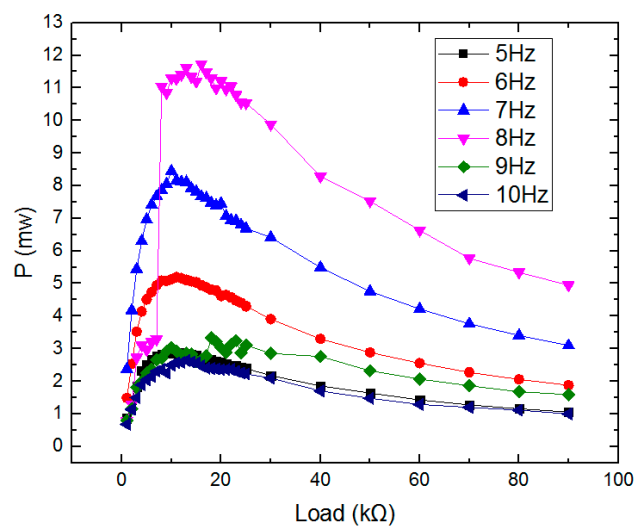

(c)

Figure 13. Output power versus load resistance at different frequencies: (a) under $0.1 \mathrm{~g}$; (b) under $0.2 \mathrm{~g}$; (c) under $0.3 \mathrm{~g}$.

\subsection{Experiments of the PMC and the Self-Powered Wireless Sensor Node}

A PMC with the components given in Table 2 was designed to power the wireless sensor node. The rectifiers were composed of Schottky diodes, with a very low threshold voltage. The comparator used in the square wave generation circuit is the same as the comparator of the voltage detection circuit, which has the characteristic of low power consumption. The energy storage device was a $14.7 \mathrm{mF}$ capacitor.

Table 2. Components used in the proposed PMC.

\begin{tabular}{ccc}
\hline Component & Part Number & Comments \\
\hline N-MOSFET & $2 \mathrm{~N} 7002$ & $R_{o n}=3.5 \Omega ; \mathrm{t}_{\text {on }}=10 \mathrm{~ns} ; \mathrm{t}_{\text {off }}=15 \mathrm{~ns} ;$ \\
Schottky diode & $\mathrm{SS} 14$ & $C_{\text {oss }}=22 \mathrm{pF} ; C_{i s s}=25 \mathrm{pF}$ \\
Comparator A1 & LTC1540 & $V_{F}=0.4 \mathrm{~V}$ \\
Inductor & - & $\mathrm{I}_{q}=0.3 \mu \mathrm{A}$ \\
Comparator A2 & LTC1540 & $\mathrm{L}=10 \mathrm{mH} ; \mathrm{DCR}=0.63 \Omega$ \\
Voltage regulator & TPS70933 & $\mathrm{I}_{q}=0.3 \mu \mathrm{A}$ \\
\hline
\end{tabular}

The wireless sensor node module included a humidity and temperature sensor (SHT11), a low-power 16-bit microprocessor (MSP430, Texas Instruments, Dallas, TX, USA), and a low-power transceiver (CC2530, Texas Instruments, Dallas, USA). A low-dropout regulator (LDO, TPS709, Texas Instruments, Dallas, USA) was used to provide a stable voltage for the wireless sensor node. The whole system of the self-power wireless sensor consisted of the energy harvester, the PMC, and the wireless sensor node. The experimental setup for the characterization of the self-powered 
wireless sensor node is given in Figure 14. The voltage across the storing capacitor was monitored by the oscilloscope.

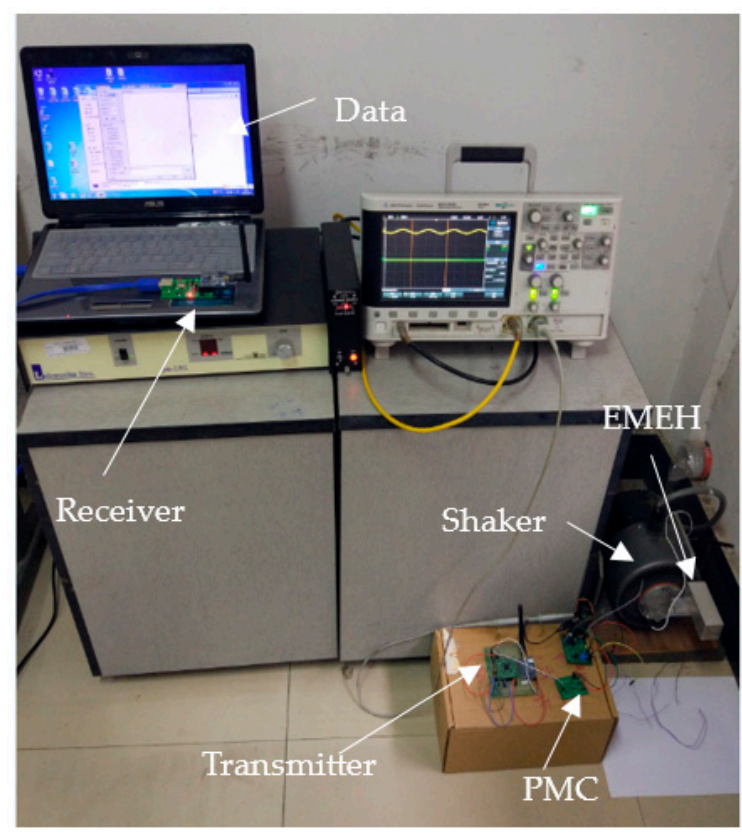

Figure 14. Setup for performance measurements of the self-powered wireless sensor node.

To characterize the square control signal, the output waveform of the control circuit was measured by the oscilloscope, as shown in Figure 15. The duty ratio and frequency of the square wave generator circuit are $3.8 \%$ and $1 \mathrm{kHz}$, respectively.

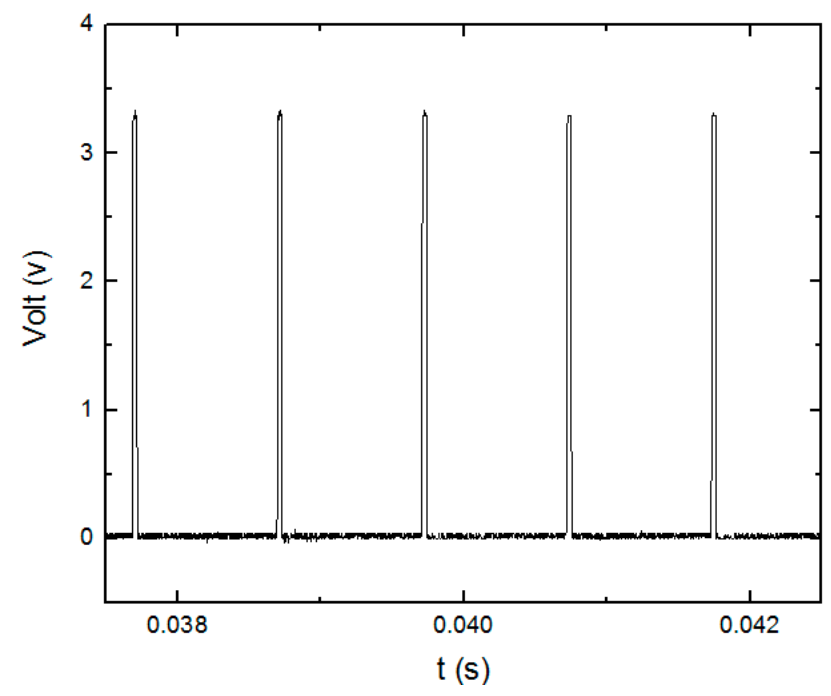

Figure 15. Square-wave control signal.

Two different PMCs, the SEH circuit and the proposed PMC, were used to drive the self-powered wireless sensor, separately. For the SEH circuit, all the 14 coils were used to charge the storage capacitor. For the proposed PMC, 10 coils were used to charge the storage capacitor and the other 4 coils were used to power the switch control branch. The upper and lower threshold voltages were set as $5.2 \mathrm{~V}$ and $2.5 \mathrm{~V}$, respectively. Under base excitation of $0.3 \mathrm{~g}$ at $8 \mathrm{~Hz}$, the experimental voltage waveforms across the storage capacitor are given in Figure 16. By using an LDO regulator, a stable voltage can be provided to the wireless sensor node. The operating voltages of sensor, microprocessor and transmitter 
were $3.3 \mathrm{~V}$. To charge a $14.7 \mathrm{mF}$ storage capacitor from 0 to $5.2 \mathrm{~V}$, the harvesting system with the SEH circuit needed 115 seconds and that with the proposed PMC needed 46 seconds. As the power source of the wireless sensor node, to charge the storage capacitor from 2.5 to $5.2 \mathrm{~V}$, the systems with the SEH and with the proposed PMC needed 66 seconds and 32 seconds, respectively. Therefore, compared with the common SEH circuit, the proposed PMC significantly shortens the intermittent operating period of the wireless sensor node.

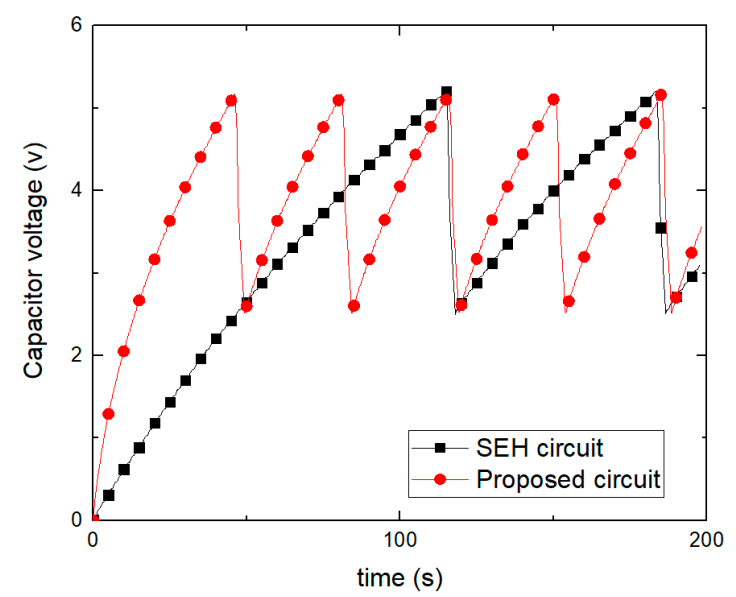

Figure 16. Voltage waveforms across the storing capacitor.

The stored energy and the average charging power can be expressed as:

$$
W_{\text {out }}=\frac{1}{2} C\left(U_{2}^{2}-U_{1}^{2}\right)=\frac{1}{2} \times 14.7 \times\left(5.2^{2}-2.5^{2}\right) \mathrm{mJ}=152.8 \mathrm{~mJ},
$$

and

$$
P_{\text {out }}=\frac{W_{\text {out }}}{t}=\frac{152.8 \mathrm{~mJ}}{32 \mathrm{~s}}=4.8 \mathrm{~mW} .
$$

From Figure 14, the experimental maximum output power across the optimal resistive load of $11 \mathrm{k} \Omega$ is:

$$
P_{\text {in }}=P_{m}=\frac{U^{2}}{R}=11.5 \mathrm{~mW}
$$

Thus, the efficiency of the proposed PMC can be obtained for an excitation of $0.3 \mathrm{~g}$ at $8 \mathrm{~Hz}$ is given by [25,29]:

$$
\eta=\frac{P_{\text {out }}}{P_{\text {in }}}=\frac{P_{\text {out }}}{P_{m}}=41.7 \%
$$

Table 3 compares the performances of the proposed harvesting system for wireless sensor nodes with those reported in literature. For our system, the amplitude and the frequency of the base excitation are relatively low, and the output power and the storage capacitor are large enough to power many wireless sensor nodes. The charging time interval is the preparation time for the intermittent operation of the wireless sensor nodes. The charging time interval of our system is the shortest.

Table 3. Comparison among energy harvesting systems for wireless sensor nodes.

\begin{tabular}{ccccccc}
\hline Reference & Amplitude & Frequency & $\begin{array}{c}\text { Storage } \\
\text { Capacitor }\end{array}$ & Power & Efficiency & $\begin{array}{c}\text { Charging } \\
\text { Time Interval }\end{array}$ \\
\hline Zhu 2011 [37] & $0.4 \mathrm{~g}$ & $67 \mathrm{~Hz}$ & $0.55 \mathrm{~F}$ & $240 \mu \mathrm{W}$ & - & $800 \mathrm{~s}$ \\
Szarka 2012 [24] & $0.15 \mathrm{~g}$ & $43.6 \mathrm{~Hz}$ & $12.8 \mathrm{mF}$ & $0.9 \mathrm{~mW}$ & $65 \%$ & $1440 \mathrm{~s}$ \\
Shen 2016 [29] & $0.99 \mathrm{~g}$ & $4 \mathrm{~Hz}$ & - & $31.6 \mathrm{~mW}$ & $16.9 \%$ & $600 \mathrm{~s}$ \\
Han 2017 [36] & $0.15 \mathrm{~g}$ & $40 \mathrm{~Hz}$ & $2 \mathrm{mF}$ & $0.9-1.1 \mathrm{~mW}$ & $42 \%$ & $48-67 \mathrm{~s}$ \\
Xu 2017 [5] & $5 \mathrm{~g}$ & $52 \mathrm{~Hz}$ & $0.47 \mathrm{mF}$ & $46.06 \mu \mathrm{W}$ & - & $125 \mathrm{~s}$ \\
This work & $0.3 \mathrm{~g}$ & $8 \mathrm{~Hz}$ & $14.7 \mathrm{mF}$ & $11.5 \mathrm{~mW}$ & $41.7 \%$ & $30 \mathrm{~s}$ \\
\hline
\end{tabular}


When the excitation frequency is kept at $8 \mathrm{~Hz}$ and the excitation amplitude increases from $0.2 \mathrm{~g}$ to $0.4 \mathrm{~g}$, the experimental charging power curves of two circuits are given in Figure 17. There is a sudden jump of the charging power when the excitation amplitude increases. Similar to the jump in Figure 13, the jump in Figure 17 also comes from the effects of the external electrical resistance. The SEH circuit and the proposed PMC demonstrate different load characteristics. Therefore, when the excitation frequency is kept as $8 \mathrm{~Hz}$, the collision between the inner and the outer frames occurs at different excitation levels. The collision causes not only a sudden jump of the output power, but also a sudden jump of the charging power. From Figure 17, it is found that the collision occurs at a lower excitation level when the proposed PMC is used. For example, the collision produces high electrical outputs when the acceleration amplitude is higher than $0.25 \mathrm{~g}$ for the system with the proposed PMC, and higher than $0.34 \mathrm{~g}$ for that with the SEH circuit. This is why the charging power of the system with the proposed PMC is much higher than that with the SEH circuit under base excitation with an amplitude between $0.25 \mathrm{~g}$ and $0.33 \mathrm{~g}$. When the acceleration amplitude is larger than $0.34 \mathrm{~g}$, for both systems, the inner frame collides with the outer frame. In this case, the relative differences of the charging power between two systems are not as large as those under excitation with an amplitude between 0.25 and $0.33 \mathrm{~g}$. The experimental results show that the charging power increases from 1.63 to $4.44 \mathrm{~mW}$ under $0.3 \mathrm{~g}$, and from 3.82 to $4.91 \mathrm{~mW}$ under $0.4 \mathrm{~g}$. Therefore, the charging efficiency increases by $172 \%$ and $28.5 \%$ under 0.3 and $0.4 \mathrm{~g}$, respectively. The experiments verify that the charging efficiency of the proposed PMC is higher than that with the SEH circuit.

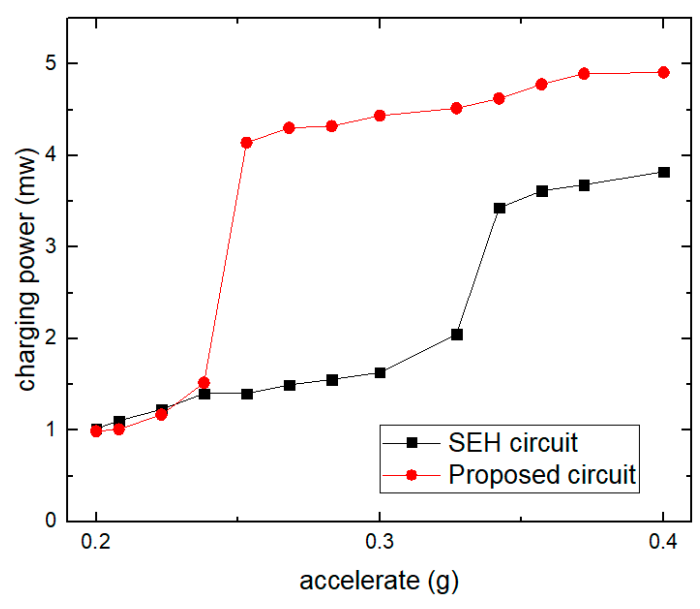

Figure 17. Charging power versus excitation levels.

\section{Conclusions}

This paper proposed a PMC for an impact-based electromagnetic energy harvester to accumulate energy and power a wireless sensor node without any external power source. The model of the nonlinear electromagnetic energy harvester with a nonlinear interface circuit was investigated and simulated. The PMC applied a buck-boost DC-DC converter to match the load resistance of the nonlinear interface circuit, instead of roughly matching the internal resistance of the harvester. To take use of the coil array of EMEH, the PMC contained two open-loop branches, and a fixed duty cycle operation of the switching converter might provide resistance matching under low frequency excitations. The PMC operated well over a wide input voltage range. The experimental results demonstrated that, compared with the SEH circuit, the proposed PMC transferred more energy from the harvester to the load and improved the charging efficiency. The power transfer efficiency of $41.7 \%$ was obtained under the base excitation of $0.3 \mathrm{~g}$ at $8 \mathrm{~Hz}$.

For simplicity, the rolling friction was neglected in the simulation in this paper. This effect should be further analyzed in the future. More works need to be conducted on the optimization method of the electrical parameters. In addition, to improve the adaptability of the harvesting system to different base excitations, a reconfigurable adaptive structure should be considered, which may automatically 
adjust the coil numbers of the two branches of the PMC and transfer excess energy from the control branch to the storage capacitor of the main branch.

Author Contributions: K.L. and X.H. proposed the idea. K.L. simulated and finished the hardware experimental work. X.W. fabricated the harvester. All the authors participated in the discussion of experimental results. The entire research project was conceived and supervised by X.H. Original draft was wrote by K.L. and X.H.; review \& editing was finished by K.L., X.H. and S.J.

Funding: This work was financially supported by the National Natural Science Foundation of China (Nos. 61774026 and 61376116), and the National Key Research and Development Program of China (Nos. 2016YFE0125200 and 2016YFC0101100).

Conflicts of Interest: The authors declare no conflict of interest.

\section{References}

1. Balato, M.; Costanzo, L.; Vitelli, M. MPPT in Wireless Sensor Nodes Supply Systems Based on Electromagnetic Vibration Harvesters for Freight Wagons Applications. IEEE Trans. Ind. Electron. 2016, 64, 3576-3586. [CrossRef]

2. Ottman, G.K.; Hofmann, H.F.; Bhatt, A.C.; Lesieutre, G.A. Adaptive piezoelectric energy harvesting circuit for wireless remote power supply. IEEE Trans. Power Electron. 2002, 17, 669-676. [CrossRef]

3. Sharma, H.; Haque, A.; Jaffery, Z.A. Modeling and Optimisation of a Solar Energy Harvesting System for Wireless Sensor Network Nodes. J. Sens. Actuator Netw. 2018, 7, 40. [CrossRef]

4. Yan, B.; Zhang, S.; Zhang, X.; Wang, K.; Wu, C. Self-powered electromagnetic energy harvesting for the low power consumption electronics: Design and experiment. Int. J. Appl. Electromagn. Mech. 2017, 54, $165-175$. [CrossRef]

5. Xu, D.; Li, S.; Li, M.; Xie, D.; Dong, C.; Li, X. A high-efficiency self-powered wireless sensor node for monitoring concerning vibratory events. Smart Mater. Struct. 2017, 26, 095038. [CrossRef]

6. Bendame, M.; Abdel-Rahman, E.; Soliman, M. Wideband, low-frequency springless vibration energy harvesters: Part I. J. Micromech. Microeng. 2016, 26, 115021. [CrossRef]

7. Asharf, K.; Khir, M.H.; Dennis, J.O. Improved energy harvesting from low frequency vibrations by resonance amplification at multiple frequencies. Sens. Actuators A Phys. 2013, 195, 123-132. [CrossRef]

8. Cao, X.; Chiang, W.J.; King, Y.C.; Lee, Y.K. Electromagnetic Energy Harvesting Circuit with Feedforward and Feedback DC-DC PWM Boost Converter for Vibration Power Generator System. IEEE Trans. Power Electron. 2007, 22, 679-685. [CrossRef]

9. Li, P.; Wen, Y.; Liu, P.; Li, X.; Jia, C. A magnetoelectric energy harvester and management circuit for wireless sensor network. Sens. Actuators A Phys. 2010, 157, 100-106. [CrossRef]

10. Szarka, G.D.; Burrow, S.G.; Proynov, P.P.; Stark, B.H. Maximum Power Transfer Tracking for Ultralow-Power Electromagnetic Energy Harvesters. IEEE Trans. Power Electron. 2013, 29, 201-212. [CrossRef]

11. Bletsas, A.; Siachalou, S.; Sahalos, J.N. Anti-collision backscatter sensor networks. IEEE Trans. Wirel. Commun. 2009, 8, 5018-5029. [CrossRef]

12. Hoang, D.T.; Niyato, D.; Wang, P.; Kim, D.I.; Le, L.B. Optimal data scheduling and admission control for backscatter sensor networks. IEEE Trans. Commun. 2017, 65, 2062-2077. [CrossRef]

13. Assimonis, S.D.; Daskalakis, S.N.; Bletsas, A. Sensitive and efficient RF harvesting supply for batteryless backscatter sensor networks. IEEE Trans. Microw. Theory Tech. 2016, 64, 1327-1338. [CrossRef]

14. Ciuonzo, D.; Buonanno, A.; Urso, M.; Palmieri, F.A. Distributed classification of multiple moving targets with binary wireless sensor networks. In Proceeding of the FUSION-The 14th international Conference on Information Fusion, Chicago, IL, USA, 5-8 July 2011.

15. Rossi, P.S.; Ciuonzo, D.; Kansanen, K.; Ekman, T. Performance analysis of energy detection for MIMO decision fusion in wireless sensor networks over arbitrary fading channels. IEEE Trans. Microw. Theory Tech. 2016, 15, 7794-7806. [CrossRef]

16. Ciuonzo, D.; Rossi, P.S.; Dey, S. Massive MIMO channel-aware decision fusion. IEEE Trans. Signal Process. 2015, 63, 604-619. [CrossRef]

17. Tarighati, A.; Gross, J.; Jalden, J. Decentralized hypothesis testing in energy harvesting wireless sensor networks. IEEE Trans. Signal Process. 2017, 65, 4862-4873. [CrossRef] 
18. Liang, J.; Liao, W. Improved Design and Analysis of Self-Powered Synchronized Switch Interface Circuit for Piezoelectric Energy Harvesting Systems. IEEE Trans. Ind. Electron. 2012, 59, 1950-1960. [CrossRef]

19. Wang, X.; Liang, X.; Hao, Z.; Du, H.; Zhang, N.; Qian, M. Comparison of electromagnetic and piezoelectric vibration energy harvesters with different interface circuits. Mech. Syst. Signal Process. 2016, 72, 906-924. [CrossRef]

20. Liang, J.; Liao, W. Impedance Modeling and Analysis for Piezoelectric Energy Harvesting Systems. IEEE/ASME Trans. Mech. 2012, 17, 1145-1157. [CrossRef]

21. Lefeuvre, E.; Badel, A.; Richard, C.; Guyomar, D. Piezoelectric Energy Harvesting Device Optimization by Synchronous Electric Charge Extraction. J. Intell. Mater. Syst. Struct. 2005, 16, 865-876. [CrossRef]

22. Arroyo, E.; Badel, A. Electromagnetic vibration energy harvesting device optimization by synchronous energy extraction. Sens. Actuators A Phys. 2011, 171, 266-273. [CrossRef]

23. Arroyo, E.; Badel, A.; Formosa, F.; Wu, Y.; Qiu, J. Comparison of electromagnetic and piezoelectric vibration energy harvesters: Model and experiments. Sens. Actuators A Phys. 2012, 183, 148-156. [CrossRef]

24. Szarka, G.D.; Burrow, S.G.; Stark, B.H. Ultralow Power, Fully Autonomous Boost Rectifier for Electromagnetic Energy Harvesters. IEEE Trans. Power Electron. 2012, 28, 3353-3362. [CrossRef]

25. Zhu, S.; Shen, W.; Xu, Y. Linear electromagnetic devices for vibration damping and energy harvesting: Modeling and testing. Eng. Struct. 2012, 34, 198-212. [CrossRef]

26. Luo, Q.; He, X.; Jiang, S.; Wang, X. Impact-Based Electromagnetic Energy Harvester with High Output Voltage under Low-Level Excitations. Energies 2017, 10, 1848. [CrossRef]

27. Zhang, H.; Lawrence, R.C.; Ma, T. Effects of electrical loads containing non-resistive components on electromagnetic vibration energy harvester performance. Mech. Syst. Signal Process. 2018, 101, 55-66. [CrossRef]

28. Lefeuvre, E.; Audigier, D.; Richard, C.; Guyomar, D. Buck-Boost Converter for Sensorless Power Optimization of Piezoelectric Energy Harvester. IEEE Trans. Power Electron. 2007, 22, 2018-2025. [CrossRef]

29. Shen, W.; Zhu, S.; Zhu, H. Experimental study on using electromagnetic devices on bridge stay cables for simultaneous energy harvesting and vibration damping. Smart Mater. Struct. 2016, 25, 065011. [CrossRef]

30. Kong, N.; Dong, S.; Erturk, A.; Daniel, J. Resistive Impedance Matching Circuit for Piezoelectric Energy Harvesting. J. Intell. Mater. Syst. Struct. 2010, 21, 1293-1302. [CrossRef]

31. Guo, T.; Lerley, R.; Ha, D.S. Development of a power conditioning circuit for railcar energy harvesting. In Proceeding of the MWSCAS-The 56th international Midwest Symposium on Circuits and Systems, Columbus, OH, USA, 4-7 August 2013; pp. 513-516.

32. Chen, N.; Jung, H.J.; Jabbar, H.; Sung, T.H.; Wei, T. A Piezoelectric impact-induced vibration cantilever energy harvester from Speed Bump with a Low-power Power Management Circuit. Sens. Actuators A Phys. 2016, 254, 134-144. [CrossRef]

33. Chen, N.; Wei, T.; Dong, H.; Jung, H.J.; Lee, S. Alternating Resistive Impedance Matching for an Impact-Type Micro Wind Piezoelectric Energy Harvester. IEEE Trans. Ind. Electron. 2018, 65, 7374-7382. [CrossRef]

34. Xia, H.; Chen, R.; Ren, L.; Zhou, Q. Direct calculation of source impedance to adaptive maximum power point tracking for broadband vibration energy harvesting. J. Intell. Mater. Syst. Struct. 2016, 28, 1105-1114. [CrossRef]

35. Haroun, A.; Yamada, I.; Warisawa, S. Study of electromagnetic vibration energy harvesting with free/impact motion for low frequency operation. J. Sound Vib. 2015, 349, 389-402. [CrossRef]

36. Han, Y.; Feng, Y.; Yu, Z.; Lou, W.; Liu, H. A Study on Piezoelectric Energy-Harvesting Wireless Sensor Networks Deployed in a Weak Vibration Environment. IEEE Sens. J. 2017, 17, 6770-6777. [CrossRef]

37. Zhu, D.; Beeby, S.P.; Tudor, M.J.; Harris, N.R. A credit card sized self-powered smart sensor node. Sens. Actuators A Phys. 2011, 169, 317-325. [CrossRef]

(C) 2019 by the authors. Licensee MDPI, Basel, Switzerland. This article is an open access article distributed under the terms and conditions of the Creative Commons Attribution (CC BY) license (http://creativecommons.org/licenses/by/4.0/). 